\title{
Effect of night light regimen on growth performance, antioxidant status and health of broiler chickens from 1 to 21 days of age
}

\author{
R. X. Zhao', C. H. Cai', P. Wang ${ }^{1}$, L. Zheng' ${ }^{1}$, J. S. Wang ${ }^{1}$, K. X. Li', W. Liu', \\ X. Y. Guo ${ }^{1}$, X. A. Zhan ${ }^{1, *}$, and K. Y. Wang ${ }^{2, *}$
}

\author{
* Corresponding Authors: \\ X. A. Zhan \\ Tel: +86-0571-88982127, Fax: +86-0571-88982650, \\ E-mail: xazan@zju.edu.cn \\ K. Y. Wang \\ Tel: +86-0571-88982490, Fax: +86-0571-86986442, \\ E-mail: zjuwky@zju.edu.cn
}

${ }^{1}$ Feed Science Institute, College of Animal Science, Zhejiang University, Hangzhou 310058, China

2 Department of Biosystems Engineering, College of

Biosystems Engineering and Food Science, Zhejiang

University, Hangzhou 310058, China

ORCID

R. X. Zhao

https://orcid.org/0000-0001-9231-8937

C. H. Cai

https://orcid.org/0000-0002-7952-2869

P. Wang

https://orcid.org/0000-0001-8020-2099

L. Zheng

https://orcid.org/0000-0002-1592-6493

J. S. Wang

https://orcid.org/0000-0002-2828-4442

K. X. Li

https://orcid.org/0000-0002-6370-8968

W. Liu

https://orcid.org/0000-0001-8914-6046

X. Y. Guo

https://orcid.org/0000-0002-1848-0407

X. A. Zhan

https://orcid.org/0000-0001-6848-058X

K. Y. Wang

https://orcid.org/0000-0003-4287-7508

Submitted Jul 10, 2018; Revised Sept 4, 2018; Accepted Oct 5, 2018
Objective: The study was conducted to evaluate the effects of night light regimen on growth performance, antioxidant status and health of Lingnan Yellow broiler chickens from 1 to 21 days of age.

Methods: A completely randomized factorial design involved 2 photoperiods (constant lighting [CL], 24 L:0 D and intermittent lighting [INL], 17 L:3 D:1 L:3 D) $\times 2$ light intensities (10 lx and $30 \mathrm{~lx})$. A total of one thousand six hundred and eighty 1-d-old Lingnan Yellow broiler chicks were randomly divided into 4 treatments with 6 replicates (70 birds per replicate). The experiment lasted for $21 \mathrm{~d}$.

Results: Photoperiods and light intensities had no effect on average daily gain, feed conversion ratio, and mortality of the broiler chickens ( $p>0.05$ ). The INL had a significant effect on average daily feed intake $(\mathrm{p}<0.05)$ of broiler chickens compared with CL. Photoperiod and light intensity had an interactive effect on melatonin (MT) concentration $(\mathrm{p}<0.05)$. At $\mathrm{CL}$, reducing light intensity increased MT concentration; INL birds had higher MT but MT concentration was not affected by light intensity. There was an interactive effect on glutathione peroxidase (GPx) and catalase (CAT) in serum and total antioxidant capability (T-AOC) in liver between photoperiod and light intensity. With the decrease of light intensity, the activities of GPx and CAT in serum and T-AOC in liver increased in CL group $(\mathrm{p}<0.05)$. Broiler chickens reared under INL had better antioxidant status and $10 \mathrm{~lx}$ treatments had higher activities of CAT in serum than $30 \mathrm{~lx}(\mathrm{p}<0.05)$. Different photoperiods and light intensities had no effect on malondialdehyde. There was an interaction between photoperiod and light intensity on serum creatine kinase $(\mathrm{CK})$ concentration $(\mathrm{p}<0.05)$. At $\mathrm{CL}$, the elevated light intensity resulted in an increase in CK content; INL birds had lower CK concentration especially in low light intensity group. Besides, INL and low light intensity significantly reduced the concentration of serum corticosterone and heat shock protein 70 ( $\mathrm{p}<0.05)$. Serum immunoglobulin $\mathrm{M}$ contents were increased in broiler chickens reared under the INL compared with CL group $(\mathrm{p}<0.05)$.

Conclusion: Results above suggest that the night light regimen of INL and $10 \mathrm{~lx}$ could be beneficial to the broiler chickens from 1 to 21 days of age due to the better health status and electricity savings.

Keywords: Night Light Regimen; Broiler Chickens; Growth Performance; Antioxidant Status; Health

\section{INTRODUCTION}

With the intensification and standardization of modern poultry industry, themicreenvironment has a great impact on the health and production performance of poultry. Lighting is one of the most important environmental factors affecting broiler performance and physical activity. It not only allows birds to establish rhythmicity and synchronize physiology, but also stimulates secretion patterns of several hormones controlling growth, maturation, and repro- 
duction [1]. Therefore, broiler chickens reared under appropriate lighting regimens may have better performance as well as welfare advantages [2].

The different aspects of light, consisting of light intensity, duration and wavelength, have been studied in recent decades and more attention has been paid to light duration (photoperiod). Researches on different photoperiods mainly includes; continuous lighting (CL) and intermittent lighting (INL). The CL contains $24 \mathrm{~h}$ of light (L) and INL contains 2 or more light and dark (D) cycles in $24 \mathrm{~h}$. Sönmez concluded that INL (12 L:3[1 L:3 D]) can improve the growth performance and reduce fast growth-related diseases, such as leg problems, sudden death syndrome and ascites of broiler chickens compared to the CL [3]. Broiler chickens reared under the INL (1 L:3 D cycles, repeated six times) compared to the CL had lower mortality and plasma $\mathrm{T}_{3}$ levels [4]. However, others like Renden et al [5] reported no difference in the growth performance of birds raised under INL when compared to those raised under CL.

Besides, light intensity is also one aspect of light management that could have important consequences for broiler behavior, performance and welfare. Reducing light intensity stimulated feed consumption and a subsequent body weight (BW) improvement, as compared with high-intensity lighting [6]. The results of Deep showed 1 lx light intensity treatment had a negative effect on broiler welfare as demonstrated by increased ulcerative footpad lesions and eye size compared with higher light intensity $(10,20$, and $40 \mathrm{~lx})$ [7]. Others found that there was no effect of light intensity on broiler chickens' growth performance $[8,9]$.

The results from our previous studies have demonstrated that compared to $16 \mathrm{~L}: 2 \mathrm{D}: 1 \mathrm{~L}: 2 \mathrm{D}: 1 \mathrm{~L}: 2 \mathrm{D}$ group, the $17 \mathrm{~L}: 3$ D:1 L:3 D group can enhance the antioxidant status of broiler chickens [10]. More studies are necessary to examine the effects of photoperiod, light intensity and their interaction on broiler chickens under commercial farming practice to assess the light program that maximizes growth performances with minimal negative impacts on broiler health. Thus, the study was conducted to evaluate the effects of night light regimen on growth performance, antioxidant status and health of broiler chickens from 1 to 21 days of age to determine the proper night light regimen for commercial raising.

\section{MATERIALS AND METHODS}

The project was conducted under the supervision of Zhejiang University Animal Care and Use Committee (Hangzhou, China), which has adopted animal care and use guidelines governing all animal use in experimental producers [11-13].

\section{Experimental design and treatments}

To examine the effects of night light regimen on broiler chickens, a completely randomized design involving 2 photoperiods $\times 2$ light intensities was used in this experiment. The 2 photoperiods were CL (24 L:0 D) and INL (17 L:3 D:1 L:3 D). During the daytime we used natural light and the illumination was provided by incandescent bulbs at night. Automatic timers (KG316T, Xiangyang Electronic Co., Ltd., Zhejiang, China) were used for different lighting photoperiods. The intermittent cycle began at 20:00 and finished at 03:00 for INL. The 2 light intensities were $10 \mathrm{~lx}$ and $30 \mathrm{~lx}$. Light intensity was measured along a horizontal plane at $25 \mathrm{~cm}$ above the litter using a light meter (VICTOR 1010C, Shenzhen City Station Win Technology Co., Ltd., Guangdong, China) 3 times each week. Therefore, there were a total of 4 treatments $(\mathrm{CL} / 10 \mathrm{~lx}, \mathrm{CL} / 30 \mathrm{~lx}, \mathrm{INL} / 10 \mathrm{~lx}$, $\mathrm{INL} / 30 \mathrm{~lx}$ ) in this experiment.

\section{Animals and diets}

A total of one thousand six hundred and eighty 1-d-old Lingnan Yellow broiler chicks were obtained from a local commercial hatchery (Zhejiang Yixing Industry Co. Ltd., Jiaxing, China) and randomly divided into four treatments with 6 replicates of 70 birds per replicate based on BW. Four groups of broiler chickens were housed in four rooms with similar environments except the light regimen. The room temperature was set initially at $33^{\circ} \mathrm{C}$ and gradually reduced by $3^{\circ} \mathrm{C}$ per week. The birds were provided with clean water and fed ad-libitum during the experimental period. Birds were reared in floor pens cover with fresh wood shavings. The experiment lasted for $21 \mathrm{~d}$.

A corn-soybean meal basal diet was formulated to meet the nutrient requirement guidelines of the NRC [14]. The ingredients and nutrient content of the maternal basal diets are shown in Table 1 [14].

\section{Sample collection and preparation}

At the end of the $21 \mathrm{~d}$ experiment, 4 birds ( 2 males and 2 females) were randomly selected per replicate from each treatment. Feed was withdrawn from the birds approximately $12 \mathrm{~h}$ before slaughter. Blood samples (5.0 mL per birds) were collected from the main wing vein and placed in coagulant tubes. Then, the birds were slaughtered to obtain the liver (part of the liver left lobe). Serum was separated by centrifugation at $4^{\circ} \mathrm{C}, 3,000$ $\mathrm{rpm} / \mathrm{min}$ for $10 \mathrm{~min}$. All samples were frozen directly in liquid nitrogen and stored at $-80^{\circ} \mathrm{C}$ for further analysis.

\section{Growth performance}

The BW was measured at the beginning of the experiment $(1 \mathrm{~d})$ and on $21 \mathrm{~d}$. Both BW and feed intake (FI) were measured for the calculation of average daily feed intake (ADFI), average daily gain $(\mathrm{ADG})$ and feed conversion ratio (FCR). Mortality was recorded daily as it occurred. The FCR calculated as the total amount of feed consumed divided by the total BW was adjusted for the number and weight of the dead birds during the experimental period. 
Table 1. Ingredients and nutrient content of the basal diets

\begin{tabular}{lc}
\hline Item & $\mathbf{1}$ to $\mathbf{2 1} \mathbf{d}$ \\
\hline Ingredient (\%) & 54.70 \\
Corn & 5.00 \\
Wheat & 29.00 \\
Soybean meal & 6.00 \\
Corn gluten meal & 1.00 \\
Soy oil & 0.30 \\
Salt & 1.70 \\
CaHPO & \\
Limestone & 1.30 \\
Vitamin-mineral premix ${ }^{1)}$ & 1.00 \\
Composition (\%) & \\
ME') (MJ/kg) & 12.17 \\
Crude protein & 20.96 \\
Lys & 1.10 \\
Met & 0.50 \\
Met+Cys & 0.85 \\
Calcium & 0.99 \\
Total phosphorus & 0.66 \\
\hline
\end{tabular}

1) The vitamin-mineral premix supplied the followings per kilogram of diet: vitamin $\mathrm{A}, 9,600 \mathrm{lU}$; vitamin $\mathrm{D}_{3}, 2,700 \mathrm{lU}$; vitamin $\mathrm{E}, 36 \mathrm{mg}$; vitamin $\mathrm{K}_{3}, 3.0 \mathrm{mg}$; vitamin $B_{1}, 3.0$ mg; vitamin $B_{2}, 10.5$ mg; vitamin $B_{6}, 4.2 \mathrm{mg}$; vitamin $B_{12}, 0.03$ mg; folic acid, $1.5 \mathrm{mg}$; nicotinamide, $60 \mathrm{mg}$; D-calcium pantothenate, $18 \mathrm{mg}$; biotin, 0.225 mg; choline chloride, 1,000 mg; Fe, 80 mg; Cu, 8.0 mg; Mn, 80 mg; Zn, 60 mg; I, $0.35 \mathrm{mg}$; Se, $0.15 \mathrm{mg}$.

${ }^{2)}$ The metabolizable energy (ME) was calculated from data provided by Feed Database in China.

\section{Serum melatonin concentration}

Serum melatonin (MT) was measured by enzyme-linked immunosorbent assay (ELISA) and its concentration expressed as $\mathrm{pg} / \mathrm{mL}$. The MT test kit utilizes the principles of competition.

\section{Antioxidant status}

Antioxidant indexes were assayed according to the prescribed protocol using commercial kits. Serum and liver were analyzed for the activities of glutathione peroxidase (GPx), total antioxidant capability (T-AOC), catalase (CAT), and malondialdehyde (MDA).

The GPx activity was assessed using a GPx kit, which was developed based on the analysis of reduced glutathione (GSH) in the enzymatic reaction. One unit of enzyme activity represents a decrease in GSH concentration of $1 \mu \mathrm{mol} / \mathrm{mg}$ protein per minute after subtraction of non-enzymatic mode at $37^{\circ} \mathrm{C}$ [15].

2,2'-Amino-di(2-ethyl-benzothiazoline sulphonic acid-6) ammonium salt (ABTS) is oxidized to a green $\mathrm{ABTS}^{+}$under the action of a suitable oxidizing agent. The antioxidant inhibits the production of ABTS ${ }^{+}$. The absorbance of $\mathrm{ABTS}^{+}$is measured at $405 \mathrm{~nm}$ or $734 \mathrm{~nm}$ to determine and calculate the T-AOC of the sample.

The reaction of CAT to decompose $\mathrm{H}_{2} \mathrm{O}_{2}$ can be quickly stopped by the addition of ammonium molybdate, and the remaining $\mathrm{H}_{2} \mathrm{O}_{2}$ reacts with ammonium molybdate to produce a pale-yellow complex. By measuring the amount of change, the activity of CAT can be calculated.

The MDA level was determined via the method of Yagi [16]. Its principle is based on the intensity of the color after treatment of the sample with thiobarbituric acid [16].

The total protein concentration of liver was measured by Lowry method using commercial kit [17]. All kits were manufactured by Nanjing Jiancheng Bioengineering Institute (Nanjing, China).

\section{Anti-stress capacity}

Serum was analyzed for creatine kinase (CK), corticosterone (CORT) and heat shock protein 70 (HSP70) by using commercial kits manufactured by Nanjing Jiancheng Bioengineering Institute (China).

The CK catalyzes the activation of adenosine triphosphate and creatine to produce creatine phosphate. The addition of ammonium molybdate produces phosphomolybdic acid, which can be further reduced to molybdenum blue, and the activity of the enzyme can be calculated from the amount of inorganic phosphorus produced.

The CORT and $\mathrm{HSP}_{70}$ was measured by ELISA. Manufacturer's recommendations were followed during the assay.

\section{Immunity}

Concentrations of immunoglobulin A (IgA), IgM, and IgG in serum were determined by turbidimetry with commercial kits manufactured by Nanjing Jiancheng Bioengineering Institute (China). This test gave the total level of non-specific IgA, IgM, and IgG.

The IgA, IgM, and IgG in serum and the specific IgA, IgM, and IgG antibody in the reagent form an antigen-antibody complex resulting in turbidity, and its turbidity is proportional to the amount of IgA, IgM, and IgG in the serum in the presence of a certain amount of antibody. By measuring the absorbance value at a specific wavelength, the $\operatorname{IgA}, \operatorname{IgM}$, and $\operatorname{IgG}$ content in the serum can be calculated by referring to the calibration curve.

\section{Statistical analysis}

Replicate was considered as the experimental unit. Data were analyzed as a $2 \times 2$ (photoperiods $\times$ light intensities) factorial arrangement of treatments by two-way analysis of variance with a model including the main effects of photoperiods, light intensities and their interaction using the general linear model procedure of the SPSS 19.0. The values were expressed as means \pm standard error and statistical significance was set at $\mathrm{p}<0.05$.

\section{RESULTS}

\section{Growth performance}


The results of the effects of night light mode on ADG, ADFI, FCR and mortality are presented in Table 2. Photoperiods and light intensities had no effect on ADG, FCR, and mortality of the broiler chickens $(\mathrm{p}>0.05)$. The INL had significant effect on ADFI $(p<0.05)$ of broiler chickens compared with CL.

\section{Serum melatonin concentration}

As shown in Table 3. Photoperiod and light intensity had an interactive effect on MT concentration $(\mathrm{p}<0.05)$. At CL, reducing light intensity increased MT concentration; INL birds had higher MT but MT concentration was not affected by light intensity.

\section{Antioxidant status}

Table 4 and Table 5 show an interactive effect on GPx and CAT in serum and T-AOC in liver between photoperiod and light intensity. With the decrease of light intensity, the activities of GPx and CAT in serum and T-AOC in liver increased in CL group ( $\mathrm{p}<0.05)$. Broiler chickens reared under INL had better antioxidant status and $10 \mathrm{~lx}$ treatments had higher activities of CAT in serum than $30 \mathrm{~lx}(\mathrm{p}<0.05)$. Different photoperiods and light intensities had no effect on MDA.

\section{Anti-stress capacity}

Both photoperiod and light intensity affected $(\mathrm{p}<0.05)$ antistress capacity (Table 6). There was an interaction between photoperiod and light intensity on serum CK concentration $(\mathrm{p}<0.05)$. At $\mathrm{CL}$, the elevated light intensity resulted in an increase in CK content; INL birds had lower CK concentration especially in low light intensity group. Besides, INL and low light intensity significantly reduced the concentration of serum

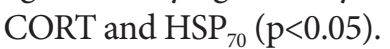

\section{Immune functions}

In Table 7, photoperiod and light intensity and their interac-
Table 3. Effects of night light mode on serum melatonin concentration of broilers (pg/mL)

\begin{tabular}{lcc}
\hline Photoperiod & Light intensity & Melatonin \\
\hline $\mathrm{CL}^{1)}$ & $30 \mathrm{~lx}$ & $55.25^{\mathrm{c}}$ \\
& $10 \mathrm{~lx}$ & $57.35^{\mathrm{b}}$ \\
$\mathrm{INL}^{2)}$ & $30 \mathrm{~lx}$ & $58.18^{\mathrm{ab}}$ \\
& $10 \mathrm{~lx}$ & $59.21^{\mathrm{a}}$ \\
$\mathrm{SEM}$ & & 0.287 \\
$\mathrm{CL}^{1)}$ & - & 56.30 \\
$\mathrm{INL}^{2)}$ & - & 58.70 \\
- & $30 \mathrm{~lx}$ & 56.71 \\
- & $10 \mathrm{~lx}$ & 58.28 \\
$\mathrm{p}^{1}-\mathrm{value}$ & Photoperiod & $<0.001$ \\
& Light intensity & 0.134 \\
& Photoperiod $\times$ light intensity & $<0.001$ \\
\hline
\end{tabular}

Values are means of six replicates $(n=6)$.

$\mathrm{CL}$, constant lighting; INL, intermittent lighting; SEM, standard error of the mean.

${ }^{1)} \mathrm{CL}=24 \mathrm{~L}: 0 \mathrm{D} .{ }^{2)} \mathrm{INL}=17 \mathrm{~L}: 3 \mathrm{D}: 1 \mathrm{L:}: 3 \mathrm{D}$.

$a, b, c$ Means in a column with different superscripts are significantly different $(p<0.05)$.

tion did not affect ( $\mathrm{p}>0.05)$ concentrations of IgG and IgA, but serum IgM contents were increased in broiler chickens reared under the INL compared with CL group $(\mathrm{p}<0.05)$.

\section{DISCUSSION}

Our results revealed that different photoperiods and light intensities had no effect on ADG, FCR, and mortality. Similar results have been reported by Bayram, who found that there were no significant differences between $16 \mathrm{~L}: 8 \mathrm{D}$ group and $24 \mathrm{~L}: 0$ D group in BW and FCR at 6 wk [18]. Ahmad et al [19] reported that there was no effect of various light intensities on overall growth performance of broiler chickens. Olanrewaju et al [20] compared $5 \mathrm{~lx}$ to $20 \mathrm{~lx}$ and did not report any significant difference in growth performance. However, Olanrewaju

Table 2. Effect of night light mode on growth performance of broilers

\begin{tabular}{|c|c|c|c|c|c|}
\hline Photoperiod & Light intensity & ADG (g) & ADFI (g) & FCR $(g / g)$ & Mortality (\%) \\
\hline \multirow[t]{2}{*}{$\mathrm{CL}^{1)}$} & $30 \mathrm{~lx}$ & 22.04 & 34.41 & 1.56 & 0.71 \\
\hline & $10 \mathrm{~lx}$ & 22.10 & 34.31 & 1.55 & 1.19 \\
\hline \multirow[t]{2}{*}{$\mathrm{INL}^{2)}$} & $30 \mathrm{~lx}$ & 22.14 & 35.35 & 1.60 & 1.43 \\
\hline & $10 \mathrm{~lx}$ & 22.83 & 36.76 & 1.61 & 0.95 \\
\hline SEM & & 0.196 & 0.363 & 0.012 & 0.262 \\
\hline$C L^{1)}$ & - & 22.07 & 34.36 & 1.56 & 0.95 \\
\hline $\mathrm{INL}^{2)}$ & - & 22.49 & 36.05 & 1.60 & 1.19 \\
\hline- & $30 \mathrm{~lx}$ & 22.09 & 34.88 & 1.58 & 1.07 \\
\hline- & $10 \mathrm{~lx}$ & 22.47 & 35.54 & 1.58 & 1.07 \\
\hline \multirow[t]{3}{*}{$p$-value } & Photoperiod & 0.320 & 0.009 & 0.524 & 0.659 \\
\hline & Light intensity & 0.370 & 0.219 & 0.222 & 1.000 \\
\hline & Photoperiod $\times$ light intensity & 0.453 & 0.164 & 0.831 & 0.815 \\
\hline
\end{tabular}

Values are means of six replicates $(n=6)$.

$A D G$, average daily gain; $A D F I$, average daily feed intake; $F C R$, feed conversion ratio; $C L$, constant lighting; INL, intermittent lighting.

1) $\mathrm{CL}=24 \mathrm{~L}: 0 \mathrm{D} .{ }^{2)} \mathrm{INL}=17 \mathrm{L:3} \mathrm{D:1} \mathrm{L:3} \mathrm{D}$. 
Table 4. Effects of night light mode on serum antioxidant status of broilers

\begin{tabular}{|c|c|c|c|c|c|}
\hline Photoperiod & Light intensity & $\mathrm{GPx}(\mathrm{U} / \mathrm{mL})$ & T-AOC (U/mL) & CAT (U/mL) & MDA (nmol/mL) \\
\hline \multirow[t]{2}{*}{$\overline{\mathrm{CL}^{1)}}$} & $30 \mathrm{~lx}$ & $3,939^{b}$ & 8.11 & $2.38^{c}$ & 3.70 \\
\hline & $10 \mathrm{~lx}$ & $5,804^{\mathrm{a}}$ & 8.24 & $3.17^{\mathrm{ab}}$ & 3.99 \\
\hline \multirow[t]{2}{*}{$\mathrm{INL}^{2)}$} & $30 \mathrm{~lx}$ & $5,964^{\mathrm{a}}$ & 9.97 & $2.89^{b}$ & 3.73 \\
\hline & $10 \mathrm{~lx}$ & $6,087^{\mathrm{a}}$ & 8.50 & $3.37^{\mathrm{a}}$ & 3.43 \\
\hline SEM & & 145,870 & 0.306 & 0.092 & 0.082 \\
\hline$\left(L^{1)}\right.$ & - & 4,871 & 8.17 & 2.77 & 3.85 \\
\hline $\mathrm{INL}^{2)}$ & - & 6,025 & 9.23 & 3.13 & 3.58 \\
\hline- & $30 \mathrm{~lx}$ & 4,951 & 9.04 & 2.64 & 3.71 \\
\hline- & $10 \mathrm{~lx}$ & 5,945 & 8.37 & 3.27 & 3.71 \\
\hline \multirow[t]{3}{*}{$p$-value } & Photoperiod & $<0.001$ & 0.080 & 0.023 & 0.100 \\
\hline & Light intensity & $<0.001$ & 0.261 & 0.016 & 0.989 \\
\hline & Photoperiod $\times$ light intensity & $<0.001$ & 0.182 & $<0.001$ & 0.073 \\
\hline
\end{tabular}

Values are means of six replicates $(n=6)$.

GPx, glutathione peroxidase; T-AOC, total antioxidant capability; CAT, catalase; MDA, malondialdehyde; CL, constant lighting; INL, intermittent lighting; SEM, standard error of the mean.

1) $\mathrm{CL}=24 \mathrm{~L}: 0 \mathrm{D} .{ }^{2)} \mathrm{INL}=17 \mathrm{~L}: 3 \mathrm{D}: 1 \mathrm{~L}: 3 \mathrm{D}$.

$a, b, c$ Means in a column with different superscripts are significantly different $(p<0.05)$.

Table 5. Effects of night light mode on liver antioxidant status of broilers

\begin{tabular}{|c|c|c|c|c|c|}
\hline Photoperiod & Light intensity & GPx (U/mgprot) & T-AOC (U/mgprot) & CAT (U/mgprot) & MDA (nmol/mgprot) \\
\hline \multirow[t]{2}{*}{$\mathrm{CL}^{1)}$} & $30 \mathrm{~lx}$ & 31.62 & $0.69^{b}$ & 2.97 & 1.04 \\
\hline & $10 \mathrm{~lx}$ & 30.89 & $1.31^{\mathrm{a}}$ & 3.14 & 1.09 \\
\hline \multirow[t]{2}{*}{$\mathrm{INL}^{2)}$} & $30 \mid x$ & 33.07 & $1.34^{\mathrm{a}}$ & 3.79 & 1.15 \\
\hline & $10 \mathrm{~lx}$ & 30.06 & $1.45^{\mathrm{a}}$ & 3.56 & 1.12 \\
\hline SEM & & 1.124 & 0.058 & 0.141 & 0.039 \\
\hline$C L^{1)}$ & - & 31.25 & 1.00 & 3.05 & 1.06 \\
\hline$\left(\mathrm{NL}^{2)}\right.$ & - & 31.57 & 1.39 & 3.68 & 1.13 \\
\hline- & $30 \mathrm{~lx}$ & 32.34 & 1.02 & 3.38 & 1.09 \\
\hline- & $10 \mathrm{~lx}$ & 30.48 & 1.38 & 3.35 & 1.10 \\
\hline \multirow[t]{3}{*}{$p$-value } & Photoperiod & 0.893 & $<0.001$ & 0.028 & 0.394 \\
\hline & Light intensity & 0.421 & $<0.001$ & 0.921 & 0.885 \\
\hline & Photoperiod $\times$ light intensity & 0.622 & 0.003 & 0.465 & 0.572 \\
\hline
\end{tabular}

Values are means of six replicates $(n=6)$.

GPx, glutathione peroxidase; T-AOC, total antioxidant capability; CAT, catalase; MDA, malondialdehyde; CL, constant lighting; INL, intermittent lighting; SEM, standard error of the mean.

1) $\mathrm{CL}=24 \mathrm{~L}: 0 \mathrm{D}^{2}{ }^{2)} \mathrm{INL}=17 \mathrm{L:3} \mathrm{D:1} \mathrm{L}: 3 \mathrm{D}$.

${ }^{a, b}$ Means in a column with different superscripts are significantly different $(p<0.05)$.

stated that broiler chickens subjected to a short/non-intermittent photoperiod showed the significantly lowest BW, body weight gain, and FI compared with broiler chickens reared under long/continuous (23 L:1 D) and regular/intermittent (2 L:2 D) photoperiods [21]. We found INL group had higher ADFI than CL. An increased feed consumption was also noted in broiler chickens provided $2.7 \mathrm{~lx}$ instead of $21.5 \mathrm{~lx}$ [22]. Our results showed that there was no interaction of photoperiod and light intensity on broiler chickens growth performance, this finding agreed with the results of Olanrewaju, who reported no interaction effect between 3 light intensities (10, 5.0, and $0.5 \mathrm{~lx}$ ) and 3 photoperiods (23:1 D, $2 \mathrm{~L}: 2 \mathrm{D}$, and $8 \mathrm{~L}: 16 \mathrm{D})$ on broiler chickens growth performance [20].
The MT is a neuro-hormone secreted by the pineal gland in vertebrates during darkness. Data obtained from our experiment exhibited that INL can lead to higher MT concentration compared to CL, but light intensity had no significant effect on it. Previous studies also reported that, broiler chickens reared under CL were more severely deficient in MT than those reared under INL [22]. Özkan et al [23] found that broiler chickens reared at $16 \mathrm{~L}: 8 \mathrm{D}$ had significantly higher plasma MT concentration than CL. This can be explained by Illnerová et al [24], who revealed that the duration of MT release is proportional to the length of the dark phase. In addition, Zheng et al [25] agree with our results that there was no significant difference among 4 treatments $(5,10,20,30 \mathrm{~lx})$ in serum MT 
Table 6. Effects of night light mode on serum anti-stress capacity of broilers

\begin{tabular}{|c|c|c|c|c|}
\hline Photoperiod & Light intensity & $\begin{array}{c}\text { CK } \\
\text { (U/L) }\end{array}$ & $\begin{array}{c}\text { CORT } \\
\text { (ng/mL) }\end{array}$ & $\begin{array}{c}\mathrm{HSP}_{70} \\
(\mathrm{pg} / \mathrm{mL})\end{array}$ \\
\hline \multirow[t]{2}{*}{$\mathrm{CL}^{1)}$} & $30 \mathrm{~lx}$ & $35.99^{\mathrm{a}}$ & 24.70 & 48.32 \\
\hline & $10 \mid x$ & $22.63^{b}$ & 18.21 & 31.44 \\
\hline \multirow[t]{2}{*}{$\mathrm{INL}^{2)}$} & $30 \mathrm{~lx}$ & $21.57^{b}$ & 14.79 & 35.59 \\
\hline & $10 \mathrm{~lx}$ & $15.63^{c}$ & 12.46 & 18.10 \\
\hline SEM & & 1.436 & 1.156 & 1.895 \\
\hline $\mathrm{CL}^{1)}$ & - & 29.31 & 21.46 & 39.83 \\
\hline $\mathrm{INL}^{2)}$ & - & 18.60 & 13.62 & 28.81 \\
\hline- & $301 x$ & 28.78 & 19.75 & 43.87 \\
\hline- & $101 x$ & 19.13 & 15.33 & 24.77 \\
\hline \multirow[t]{3}{*}{$p$-value } & Photoperiod & $<0.001$ & $<0.001$ & 0.002 \\
\hline & Light intensity & $<0.001$ & 0.022 & $<0.001$ \\
\hline & Photoperiod $\times$ light intensity & 0.033 & 0.269 & 0.486 \\
\hline
\end{tabular}

Values are means of six replicates $(n=6)$.

CK, creatine kinase; CORT, corticosterone; $\mathrm{HSP}_{70}$, heat shock protein 70; $\mathrm{CL}$, constant lighting; INL, intermittent lighting; SEM, standard error of the mean.

1) $\mathrm{CL}=24 \mathrm{~L}: 0 \mathrm{D} .{ }^{2)} \mathrm{INL}=17 \mathrm{L:3} \mathrm{D:1} 1 \mathrm{L:3} \mathrm{D}$.

$a, b, c$ Means in a column with different superscripts are significantly different $(p<0.05)$.

concentration of broiler chickens. Illumination could decrease MT concentration in systematic circulation when light intensity is above $500 \mathrm{~lx}$ in Syrian hamsters, sheep and monkeys [26-28]. Because the secretion of MT is only inhibited when the light intensity reaches a certain intensity, light intensity used in the present study may have not been sufficient enough to cause an obvious difference.

In the process of raising broiler chickens, adjusting the light in the environment can influence the secretion of MT and indirectly regulate the antioxidant status of the body. Apart from its direct free radical scavenging properties, MT plays a crucial role in the antioxidant system because it can promote the production of GPx, the main antioxidant enzyme in the brain $[29,30]$. The enzymes of GPx and CAT play an important role in scavenging oxygen free radicals and protecting cells from damage due to oxidation by free radicals and lipid peroxides. Tyssandier et al [31] reported that T-AOC can be used as a comprehensive index to measure the antioxidant status of the body. The MDA is one of the final products of polyunsaturated fatty acids peroxidation in the cells. Its level is commonly known as a marker of oxidative stress and the antioxidant status [32]. A study by Guo et al [33] showed 12 L:12 D decreased serum MDA and enhanced oxidant-antioxidant balance compared with 23 L:1 D, 20 L:4 D, and 16 L:8 D. Zheng et al [10] demonstrated that 3 D:1 L significantly enhanced the total T-AOC and GSH-Px. These findings agree with our results that INL groups had better antioxidant status compared to CL groups. Zheng et al [25] reported that low light intensity of $5 \mathrm{~lx}$ significantly enhanced T-AOC and activity of GPX of 21d broiler chickens both in serum and liver. Similar results were observed in our study. Besides, there was an interactive effect on GPx
Table 7. Effects of night light mode on serum contents of immunoglobulins of broilers

\begin{tabular}{lcccc}
\hline Photoperiod & Light intensity & $\begin{array}{c}\text { IgG } \\
(\mathbf{n g} / \mathbf{m L})\end{array}$ & $\begin{array}{c}\mathbf{I g M} \\
(\mathbf{n g} / \mathbf{m L})\end{array}$ & $\begin{array}{c}\mathbf{I g A} \\
(\mathbf{n g} / \mathbf{m L})\end{array}$ \\
\hline $\mathrm{CL}^{1)}$ & $30 \mathrm{~lx}$ & 311.4 & 180.4 & 6.25 \\
& $10 \mathrm{~lx}$ & 314.0 & 179.1 & 6.26 \\
$\mathrm{INL}^{2)}$ & $30 \mathrm{~lx}$ & 314.1 & 184.5 & 6.27 \\
& $10 \mathrm{~lx}$ & 313.6 & 200.6 & 6.33 \\
$\mathrm{SEM}$ & & 0.376 & 3.264 & 0.012 \\
$\mathrm{CL}^{1)}$ & - & 312.7 & 179.7 & 6.26 \\
$\mathrm{INL}^{2)}$ & - & 313.8 & 192.6 & 6.30 \\
- & $30 \mid x$ & 312.7 & 182.4 & 6.26 \\
- & $10 \mid x$ & 313.8 & 189.9 & 6.30 \\
$\mathrm{p}-\mathrm{value}$ & Photoperiod & 0.107 & 0.044 & 0.069 \\
& Light intensity & 0.139 & 0.236 & 0.103 \\
& Photoperiod $\times$ light intensity & 0.133 & 0.165 & 0.245 \\
\hline
\end{tabular}

Values are means of six replicates $(n=6)$.

Ig, immunoglobulin; CL, constant lighting; INL, intermittent lighting; SEM, standard error of the mean.

${ }^{1)} \mathrm{CL}=24 \mathrm{L:0} \mathrm{D} .{ }^{2)} \mathrm{INL}=17 \mathrm{~L}: 3 \mathrm{D}: 1 \mathrm{~L}: 3 \mathrm{D}$.

and CAT in serum and T-AOC in liver between photoperiod and light intensity. Researches about the interactive effect of photoperiod and light intensity on antioxidant status are limited.

Previous studies have shown that the anti-stress properties of MT make it possible to counteract the HPA axis dysfunction induced by exogenous glucocorticoids, and then reduce the stress caused by the rise of adreno-cortico-tropic-hormone, CORT, and other hormones [34]. Creatine kinase, which is an intracellular enzyme, will be released into the bloodstream, resulting in increased serum CK concentrations. The content of $\mathrm{CK}$ is related to the production of free radicals in the body, but MT can reduce the content of CK in the blood by scavenging free radicals. The $\mathrm{HSP}_{70}$ is one of the most conservative and important members of heat stress proteins. The level of $\mathrm{HSP}_{70}$ is low in normal cells and can be significantly elevated under stress conditions. Our results revealed that INL and low light intensity can minimize the stress compared with $\mathrm{CL}$ and high light intensity. This is supported by the finding of Olanrewaju and Buckland who reported that birds in CL group had a higher CORT concentration than INL group in their serum $[1,35]$. However, researches about the effects of light intensity on anti-stress capability are limited.

When animals are stimulated by an antigen, an immunoglobulin that specifically binds to the antigen in the body is produced. As common immunoglobulin, IgA, IgM, and IgG are of vital importance in humoral immunity. Akbulut found exogenous MT can increase IgG1 and IgM responses of aged rats [36]. This showed that MT can raise the levels of immunoglobulin in serum to some extent, which can be the reason that serum IgM contents were increased $(p<0.05)$ in broiler chickens reared under the INL compared to CL group in our experiment. Guo et al [33] reported that plasma IgG in the 
$12 \mathrm{~L}: 12 \mathrm{D}$ group was higher than in the CL group. Blatchford observed that there was no difference between different light intensities for most immune parameters, which was in accordance with our results [8].

\section{CONCLUSION}

Broiler chickens reared under INL and $10 \mathrm{~lx}$ of light intensity can increase MT concentration and improve antioxidant status, anti-stress capacity and immune function. Results above suggest that the night light regimen of INL and $10 \mathrm{~lx}$ could be beneficial to broiler chickens from 1 to 21 days of age due to the better health status and electricity saving issue.

\section{CONFLICT OF INTEREST}

We certify that there is no conflict of interest with any financial organization regarding the material discussed in the manuscript.

\section{ACKNOWLEDGMENTS}

The financial supports provided by National key R\&D Program of China (2016YFD05005) and China Agricultural Research System (CARS-42-G20) are gratefully acknowledged.

\section{REFERENCES}

1. Olanrewaju HA, Thaxton JP, Dozier WA, et al. A review of lighting programs for broiler production. Int J Poult Sci 2006;5: 301-8.

2. Sanotra GS, Lund JD, Vestergaard KS. Influence of light-dark schedules and stocking density on behaviour, risk of leg problems and occurrence of chronic fear in broilers. Br Poult Sci 2002;43:344-54.

3. Petek M, Sönmez G, Yildiz H, Baspinar H. Effects of different management factors on broiler performance and incidence of tibial dyschondroplasia. Br Poult Sci 2005;46:16-21.

4. Hassanzadeh M, Bozorgmehri Fard MH, Decuypere E. Beneficial effects of alternative lighting schedules on the incidence of ascites and on metabolic parameters of broiler chickens. Acta Vet Hung 2003;51:513-20.

5. Renden JA, Moran Jr ET, Kincaid SA. Lighting programs for broilers that reduce leg problems without loss of performance or yield. Poult Sci 1996;75:1345-50.

6. Downs KM, Lien RJ, Hess JB, Bilgili SF, Dozier WA. The effects of photoperiod length, light intensity, and feed energy on growth responses and meat yield of broilers. J Appl Poult Res 2006;15: 406-16.

7. Deep A, Schwean-Lardner K, Crowe TG, Fancher BI, Classen HL. Effect of light intensity on broiler production, processing characteristics, and welfare. Poult Sci 2010;89:2326-33.
8. Blatchford RA, Klasing KC, Shivaprasad HL, et al. The effect of light intensity on the behavior, eye and leg health, and immune function of broiler chickens. Poult Sci 2009;88:20-8.

9. Newberry RC, Hunt JR, Gardiner EE. Influence of light intensity on behavior and performance of broiler chickens. Poult Sci 1988;67:1020-5.

10. Zheng L, Ma YE, Gu LY, et al. Growth performance, antioxidant status, and nonspecific immunity in broilers under different lighting regimens. J Appl Poult Res 2013;22:798-807.

11. Animal management regulations. Beijing, China: National Assembly of the PRC; 2017.

12. Guiding opinions on the treatment of experimental animals. Beijing, China: Ministry of Science and Technology of the PRC; 2006.

13. Zhejiang province laboratory animal management measures. Hangzhou, China: Zhejiang Provincial People’s Government; 2009.

14. NRC. Nutrient requirements of poultry. 9th rev. ed. Washington, DC, USA: National Academy Press; 1994.

15. Rotruck JT, Pope AL, Ganther HE. Selenium: biochemical role as a component of glutathione peroxidase. Science 1973;179: 588-90.

16. Yagi K. Lipid peroxides and related radicals in clinical medicine. Adv Exp Med Biol 1994;366:1-15.

17. Lowry OH, Rosebrough NJ, Farr AL, Randall RJ. Protein measurement with the Folin phenol reagent. J Biol Chem 1951;193: 265-75.

18. Bayram A, Özkan S. Effects of a 16-hour light, 8-hour dark lighting schedule on behavioral traits and performance in male broiler chickens. J Appl Poult Res 2010;19:263-73.

19. Ahmad F, Haq AU, Ashraf M, Abbas G, Siddiqui MZ. Effect of different light intensities on the production performance of broiler chickens. Pak Vet J 2011;31:203-6.

20. Olanrewaju HA, Miller WW, Maslin WR, et al. Effects of light sources and intensity on broilers grown to heavy weights. Part 1: Growth performance, carcass characteristics, and welfare indices. Poult Sci 2016;95:727-35.

21. Olanrewaju HA, Purswell JL, Collier SD, Branton SL. Influence of photoperiod, light intensity and their interaction on growth performance and carcass characteristics of broilers grown to heavy weights. Int J Poult Sci 2012;11:739-46.

22. Apeldoorn EJ, Schrama JW, Mashaly MM, Parmentier HK. Effect of melatonin and lighting schedule on energy metabolism in broiler chickens. Poult Sci 1999;78:223-9.

23. Özkan S, Yalçın S, Akbaş Y, et al. Effects of short day (16L:8D) length on broilers: some physiological and welfare indices. EPC 2006 - 12th European Poultry Conference; 2006 Sep 10-14: Verona, Italy. pp. 226 ref.23.

24. Illnerová $\mathrm{H}$, Hoffmann $\mathrm{K}$, Vaněček J. Adjustment of pineal melatonin and $\mathrm{N}$-acetyltransferase rhythms to change from long to short photoperiod in the Djungarian hamster Phodopus sungorus. Neuroendocrinology 1984;38:226-31. 
25. Zheng L, Yuan D, Shi ML, Guo XY, Ma YE. Effects of light intensity on growth performance and antioxidative status of broilers. Indian J Anim Sci 2013;83:1221-5.

26. Tamarkin L, Reppert SM, Klein DC. Regulation of pineal melatonin in the Syrian hamster. Endocrinology 1979;104:385-9.

27. Rollag MD, Niswender GD. Radioimmunoassay of serum concentrations of melatonin in sheep exposed to different lighting regimens. Endocrinology 1976;98:482-9.

28. Perlow MJ, Reppert SM, Tamarkin L, Wyatt RJ, Klein DC. Photic regulation of the melatonin rhythm: monkey and man are not the same. Brain Res 1980;182:211-6.

29. Hardeland R. Antioxidative protection by melatonin: multiplicity of mechanisms from radical detoxification to radical avoidance. Endocrine 2005;27:119-30.

30. Tomás-Zapico C, Coto-Montes A. A proposed mechanism to explain the stimulatory effect of melatonin on antioxidative enzymes. J Pineal Res 2005;39:99-104.

31. Tyssandier V, Feillet-Coudray C, Caris-Veyrat C, et al. Effect of tomato product consumption on the plasma status of antioxidant microconstituents and on the plasma total antioxidant capacity in healthy subject. J Am Coll Nutr 2004;23:148-56.

32. Gaweł S, Wardas M, Niedworok E, Wardas P. Malondialdehyde (MDA) as a lipid peroxidation marker. Wiad Lek 2004;57:4535.

33. Guo YL, Li WB, Chen JL. Influence of nutrient density and lighting regime in broiler chickens: effect on antioxidant status and immune function. Br Poult Sci 2010;51:222-8.

34. Griffith MK, Minton JE. Effect of light intensity on circadian profiles of melatonin, prolactin, ACTH, and cortisol in pigs. J Anim Sci 1992;70:492-8.

35. Buckland RB, Blagrave K, Laguë PC. Competitive proteinbinding assay for corticoids in the peripheral plasma of the immature chicken. Poult Sci 1974;53:241-5.

36. Abreu VMN, Abreu PGD, Coldebella A, et al. Curtain color and lighting program in broiler production: I - general performance. R Bras Zootec 2011;40:2026-34. 